\title{
Strategi Komunikasi Politik Partai Baru (Studi Kasus Perolehan Suara Partai Solidaritas Indonesia di DPRD DKI Jakarta Pada
} Pemilu 2019)

\author{
Bella Adha Hendriana Moneter, Eko Harry Susanto \\ bella.915160234@stu.untar.ac.id,ekos@fikom.untar.ac.id \\ Fakultas Ilmu Komunikasi Universitas Tarumanagara
}

\begin{abstract}
The 2019 legislative elections participated by many political parties in Indonesia, one of which was the Indonesian Solidarity Party (PSI). The more parties that participate in the General Election, the competition between each one of them become more strict in order to get a seat in parliament. Due to that reason, PSI did not pass on the DPR RI election level but somehow managed to get a $6.68 \%$ vote and get eight seats on the Jakarta DPRD election level. In this case, the purpose of this research is to study the political communication strategy of PSI Jakarta regarding the vote they got on Jakarta DPRD election level in 2019 General Election. This research is using the conceptualization of political policy, the conceptualization of political communication strategy, conceptualization of political policy, and conceptualization of political policy. political policy, and conceptualization of general elections as the theoretical basis. The research method in this research is a case study and the research approach in this research is descriptive-qualitative. The conclusion of this research shows that the political communication strategy used by PSI Jakarta to gain votes is by paying attention to the figures, stabilizing the institution, and creating togetherness. They also combined their politics communication strategy with the politics communication itself, in order to gain a lot more votes.
\end{abstract}

Keywords: new party, psi jakarta, political communication, political party.

\begin{abstract}
Abstrak
Pemilu Legislatif Tahun 2019 diikuti banyak partai politik di Indonesia salah satunya partai baru, Partai Solidaritas Indonesia (PSI). Semakin banyak partai politik mengikuti Pemilu, semakin ketat kompetisi antar partai untuk mendapatkan kursi di parlemen. PSI tidak lolos memperebutkan kursi DPR RI, tetapi berhasil mendapatkan suara 6,68\% atau delapan kursi di DPRD DKI Jakarta. Penelitian ini ingin mengetahui strategi komunikasi politik PSI Jakarta atas perolehan suara di DPRD DKI Jakarta pada Pemilu 2019. Landasan teoritik yang digunakan adalah konseptualisasi komunikasi politik, konseptualisasi strategi komunikasi politik, konseptualisasi partai politik, dan konseptualisasi pemilihan umum. Penelitian ini menggunakan pendekatan kualitatif deskriptif. Hasil penelitian menunjukkan strategi komunikasi politik PSI Jakarta untuk memperoleh suara yakni dengan merawat ketokohan, memantapkan kelembagaan, dan menciptakan kebersamaan. PSI Jakarta juga mengkombinasikan strategi komunikasi politik dengan unsur komunikasi politik.
\end{abstract}

Kata Kunci: komunikasi politik, partai baru, partai politik, psi jakarta.

\section{Pendahuluan}

Pada 17 April 2019 lalu terjadi peristiwa penting bagi seluruh rakyat Indonesia untuk menentukan Indonesia yaitu Pemilu untuk menentukan Presiden beserta Wakil 
Presiden dan para wakil rakyat tingkat pusat maupun daerah. Pemilu pada tahun 2019 berbeda dengan Pemilu pada tahun-tahun sebelumnya. Tahun 2019, pemilihan eksekutif dan legislatif dilakukan secara serentak.

Setiap parpol yang mengikuti Pemilu memiliki visi, misi, dan juga ideologi untuk mendapatkan suara dari pemilihnya, oleh karena itu setiap partai politik harus menggunakan komunikasi politik. Tujuan komunikasi politik adalah untuk membangun citra politik, membentuk pendapat publik, serta mendorong pemilih untuk berpartisipasi dalam politik (Ardial, 2010). Komunikasi politik yang berlaku di setiap partai politik harus disesuaikan dengan sistem politik yang ada di Indonesia. Oleh karena itu, sistem komunikasi yang dilakukan oleh setiap partai politik.

Pemilihan Umum Tahun 2019 diikuti 16 partai politik nasional, ditambahkan dengan 4 partai politik lokal Aceh (kumparan.com). Dengan banyaknya partai politik yang ikut serta dalam Pemilu 2019 maka kompetisi antar partai untuk mendapatkan kursi parlemen juga semakin ketat. Keberhasilan sebuah partai politik terbukti dari perolehan suara, membuktikan betapa besarnya dukungan dan kepercayaan yang diletakkan oleh rakyat untuk partai politik tersebut.

Pemilihan umum pada masa ini berbeda dari masa sebelumnya, sebab terdapat satu partai baru yang hadir pada tahun ini partai tersebut yaitu Partai Solidaritas Indonesia (PSI). PSI dibentuk sebagai tugas untuk memberikan warna baru bagi masyarakat. Oleh karena itu, PSI ingin menyelesaikan masalah politik yang ada di Indonesia.

Berdasarkan hasil keputusan PSI merupakan partai baru yang lolos mengikuti pemilu tahun 2019. Menyandang kata partai baru, PSI salah satu partai yang sukses dibandingkan dengan partai lama lainnya seperti Hanura, PBB, Garuda, dan PKPI. Dengan mendapatkan perolehan suara 1,89\% dengan 2.650.361 pemilih. Meskipun mendapat perolehan suara yang dibilang besar untuk partai baru akan tetapi PSI tidak lolos ambang aman untuk ke DPR tahun ini, batas untuk masuk DPR yaitu 4\% (nasional.kontan.co.id).

Dari hasil perolehan suara pemilihan anggota legislatif, PSI tidak mendapat kursi Dewan Perwakilan Rakyat (DPR). Akan tetapi, PSI mendapat kursi Dewan Perwakilan Rakyat Daerah (DPRD) DKI Jakarta. Berdasarkan hasil resmi Komisi Pemilihan Umum (KPU), PSI menempati urutan ke empat dengan perolehan suara 6,86\% di DPRD DKI Jakarta (pemilu2019.kpu.go.id) setelah PDIP dengan perolehan suara 22,65\%, Gerindra dengan perolehan suara 15,86\%, dan PKS dengan perolehan suara $15,54 \%$ di DKI Jakarta dan PSI yang tergolong partai sangat baru itu dapat mengalahkan partai besar seperti PAN, Partai Nasdem, Partai Golkar, Partai Demokrat, dan Hanura.

Penelitian terdahulu yang berjudul "Brand Activation, Strategi Komunikasi Pada Lembaga Survei Politik di Putaran Pertama Pilkada DKI Jakarta 2017" mengungkapkan bahwa retorika dan propaganda merupakan satu kesatuan yang sangat mempengaruhi strategi komunikasi politik.

Hakikat strategi dalam komunikasi politik adalah memperhitungkan segala kondisi dan situasi yang akan dihadapi dan yang akan mungkin dihadapi di masa depan, guna untuk mencapai tujuan yang sudah direncanakan (Ardial, 2010).

Berdasarkan latar belakang di atas maka dilakukan penelitian untuk mengetahui gambaran mengenai strategi komunikasi politik PSI Jakarta, seperti bagaimana strategi komunikasi politik PSI Jakarta untuk memperoleh suara di Pemilu 2019? Penelitian ini dilakukan guna untuk mengetahui strategi komunikasi politik PSI Jakarta untuk memperoleh suara di Pemilu 2019 dan komunikasi politik yang 
Bella Adha Hendriana Moneter, Eko Harry Susanto: Strategi Komunikasi Politik Partai Baru (Studi Kasus Perolehan Suara Partai Solidaritas Indonesia di DPRD DKI Jakarta Pada Pemilu 2019)

digunakan PSI Jakarta. Penelitian ini dilakukan di kantor DPRD DKI Jakarta Fraksi PSI.

\section{Metode Penelitian}

Penulis menggunakan jenis penelitian kualitatif, dimana penelitian kualitatif adalah pencarian jawaban dari suatu permasalah dan peristiwa dengan mencari informasi sedalam dalamnya yang tidak dapat dihitung dengan angka atau cara kuantitatif (Sujarweni, 2014). Penulis menggunakan jenis penelitian kualitatif deskriptif dikarenakan penulis akan mencari jawaban dari suatu permasalah dan peristiwa dengan mencari informasi yang diamati dengan lisan atau tertulis dan tak dapat dihitung dengan angka.

Metode yang digunakan adalah studi kasus, dimana secara umum studi kasus merupakan metode yang cocok untuk penelitian berkenaan dengan how atau why dalam konteks yang nyata (Yin, 2013). Studi kasus digunakan sebagai metode penelitian ini dikarenakan penulis ingin mencari tahu serta mengumpulkan informasi lebih dalam pada kasus dan masalah yang ada.

Pengumpulan data yang digunakan penulis adalah wawancara, observasi, studi kepustakaan dan penelusuran data online. Subyek dalam penelitian ini adalah Public Relations PSI Jakarta, ahli komunikasi politik, DPRD terpilih PSI Jakarta, dan masyarakat yang memilih PSI Jakarta. Sedangkan obyek dalam penelitian ini adalah strategi komunikasi politik PSI Jakarta untuk memperoleh suara pada pemilu 2019.

Teknik analisis data yang digunakan dalam penelitian ini adalah teknik analisis data model Miles dan Huberman (Emzir, 2012), dibagi menjadi tiga, yaitu reduksi data, penyajian data-data, dan penarikan kesimpulan atau verifikasi. Penulis menggunakan teknik analisis data model Miles dan Huberman dengan cara mengumpulkan data dari berbagai sumber dengan melakukan wawancara mendalam, studi kepustakaan dan penelusuran data online yang akan memberikan informasi sesuai dengan topik penelitian ini. Setelah semua data terkumpul, dilanjutkan dengan melakukan reduksi data dengan memilih dan memusatkan perhatian pada data-data yang diperlukan agar lebih fokus. Kemudian, melakukan penyajian data-data yang telah dipilih sesuai dengan keadaan di lapangan penelitian untuk diteliti lebih lanjut dan kemudian barulah dilakukan penarikan kesimpulan/verifikasi mengenai strategi komunikasi politik PSI dalam kemenangannya di DPRD DKI Jakarta pada Pemilu 2019.

Teknik keabsahan data yang digunakan penulis dalam penelitian ini adalah teknik triangulasi. Triangulasi adalah teknik pemeriksaan keabsahan data yang memanfaatkan sesuatu yang lain. Diluar data itu sendiri untuk keperluan pengecekan atau pembanding terhadap data itu (Moleong, 2009:330). Penulis melakukan pengecekan data dengan cara membandingkan data hasil pengamatan dengan data wawancara yang telah peneliti dapatkan mengenai strategi komunikasi politik PSI Jakarta dalam memperoleh suara di DPRD DKI Jakarta pada pemilu 2019 dengan menggunakan teknik triangulasi, agar dapat teruji keabsahan data dan juga kebenarannya.

\section{Hasil Temuan dan Diskusi}

Dalam penelitian ini terdapat hasil temuan dan diskusi yang akan dibagi dalam konsep pembahasan sebagai berikut: 


\section{PSI Jakarta bersaing dengan strategi komunikasi politik}

Dalam pembahasan pertama penulis meneliti cara bersaing PSI Jakarta dengan partai-partai lama lainnya dengan membedakan ideologi dengan partai lainnya bisa menarik pemilih partai lain untuk pindah suara ke PSI Jakarta. Sebagian besar partai mengambil arah ideologi di tengah-tengah dan PKS mengambil ke arah kanan sedangkan PSI Jakarta mengambil arah ideologi ke kiri. Selain itu, PSI Jakarta sangat gencar menggunakan media sosial seperti Instagram, Facebook, dan lainnya untuk memperkenalkan diri kepada masyarakat bahwa ada partai baru bernama PSI untuk menampung aspirasi masyarakat DKI Jakarta.

Gambar 1: Artikel PSI Jakarta di pemberitaan Tempo

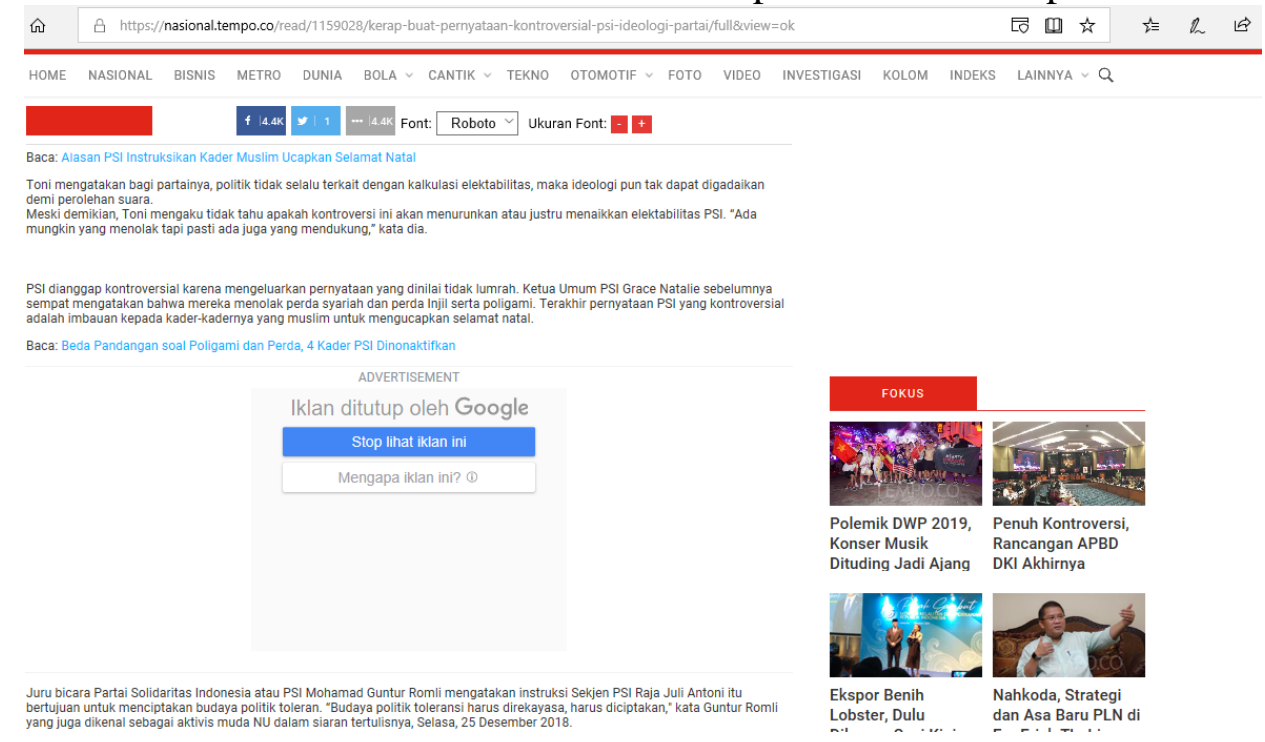

(https://nasional.tempo.co/read/1159028/kerap-buat-pernyataan-kontroversial-psiideologi-partai/full\&view $=$ ok)

Dengan demikian dapat dikatakan menjadi partai dengan ideologi atau haluan yang berbeda bisa menjadi partai pilihan masyarakat. PSI Jakarta menggunakan strategi kelembagaan dan penggunaan media sosial untuk mengambil hati pemilih.

\section{Merawat ketokohan menjadi tujuan politik PSI Jakarta}

Selain memantapkan kelembagaan, strategi lain adalah dengan merawat ketokohan dan menciptakan kebersamaan. Anwar Arifin (2011) menyatakan bahwa beberapa hasil studi menunjukkan kecenderungan pemberi suara dalam pemilihan umum untuk menjatuhkan pilihannya kepada pahlawan politik, yaitu kandidat yang sesuai dengan citra jabatan ideal baginya. Ketokohan dalam politik yang kemudian melahirkan kepahlawanan politik dan kharisma dapat diperoleh karena kredibilitas, yaitu dapat dipercaya karena karakter dan moralitas yang terpuji dalam pergaulan di tengah-tengah masyarakat.

Dalam hal ini tokoh-tokoh PSI Nasional seperti Grace Natali, Tsamara, Raja Juli, dll menjadi bank suara di DKI Jakarta. Begitu juga dengan anggota DPRD DKI Jakarta dari PSI William, dengan adanya Grace Natali, Tsamara, Ryan Ernest mengangkat suara PSI Jakarta di DPRD DKI Jakarta. 
Gambar 2. Pemberitaan ketokohan PSI di portal jawapost.com

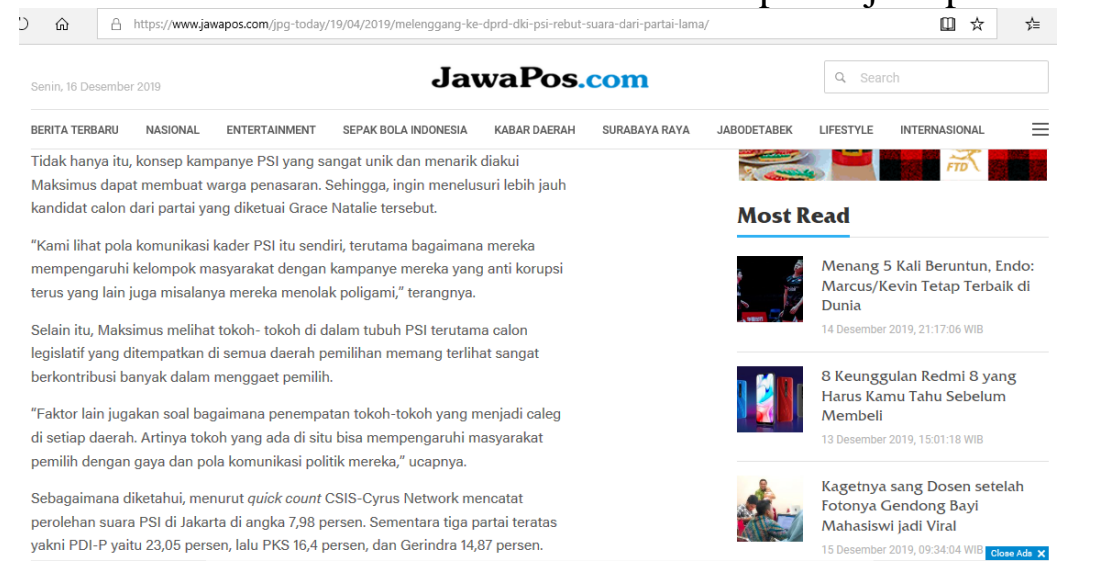

(https://www.jawapos.com/jpg-today/19/04/2019/melenggang-ke-dprd-dki-psirebut-suara-dari-partai-lama/)

Berdasarkan data portal berita jawapost.com, tokoh- tokoh di dalam tubuh PSI terutama calon legislatif yang ditempatkan di semua daerah pemilihan memang terlihat sangat berkontribusi banyak dalam menggaet pemilih. Langkah strategis selanjutnya yang harus dilakukan seorang komunikator politik untuk mencapai tujuan komunikasi politik adalah menciptakan kebersamaan antara politikus dengan masyarakat (khalayak). Hal ini dilakukan dengan cara mengenal masyarakat dan menyusun pesan politik yang sesuai dengan kondisi masyarakat tersebut (Arifin, 2011). Strategi komunikasi politik dengan membangun kebersamaan dalam bentuk fund rising yang mana PSI Jakarta bisa berkomunikasi dengan publik, blusukan dan ngopi bersama untuk dapat membangun kebersamaan bersama masyarakat.

\section{Komunikasi Politik PSI Jakarta untuk memperoleh suara pemilih}

Proses komunikasi politik terdiri atas berbagai unsur yakni: komunikator politik, pesan politik, sasaran politik, media politik, dan efek komunikasi politik (Cangara, 2011).

Komunikasi politik yang diaplikasikan PSI Jakarta untuk tujuan politiknya yang pertama adalah komunikator politik. Komunikator politiknya PSI Jakarta adalah tokoh-tokoh PSI Nasional seperti Grace Natali, Tsamara, Ryan Ernest, serta para caleg dalam PSI Jakarta dapat menarik suara para pemilih atau menjadi bank suara bagi PSI Jakarta.

Kedua, pesan politik yang ingin disampaikan oleh PSI Jakarta saat kampanye adalah anti korupsi, anti intoleransi, membela hak perempuan, partai yang terbuka, dan partainya anak muda. Selanjutnya, dengan efek komunikasi yang sampai ke masyarakat pada saat kampanye dan akhirnya masyarakat yang memilih PSI Jakarta adalah menyuarakan suara minoritas sehingga suara-suara minoritas dari menyuarakan tersebut bisa mendapatkan suara dari kaum tersebut.

Kelima, media politik yang digunakan PSI adalah televisi, media sosial, tatap muka, dan alat peraga kampanye lainnya seperti spanduk, flyer. Terakhir, yang menjadi sasaran politik dari PSI Jakarta adalah anak muda atau millenials, kaum minoritas, dan juga kaum profesional. 


\section{Simpulan}

PSI Jakarta mampu bersaing dengan partai-partai lainnya dengan cara memantapkan kelembagaan yaitu dengan membedakan ideologi atau arah partai dengan partai-partai lain yang sudah ada. PSI Jakarta menjadi partai yang tidak abuabu dengan memilih menjadi partai nasionalis. PSI Jakarta gencar menggunakan media sosial gencar untuk branding partai.

Strategi komunikasi politik yang digunakan PSI Jakarta adalah dengan merawat ketokohan. Adanya Grace Natali, Tsamara, dan tokoh lain di PSI Nasional. Selain itu juga PSI Jakarta dan caleg dari PSI Jakarta menciptakan kebersamaan dengan pemilihnya melalui Program Fund Rising, blusukan, dan memperkenalkan diri ke lingkungan daerah pilihan supaya pemilih dapat memilih caleg dari PSI Jakarta.

PSI Jakarta menggunakan seluruh unsur komunikasi politik dengan jelas untuk mendapatkan pemilih pada pemilu 2019. Dengan menerapkan hal-hal tersebut pemilih memilih PSI Jakarta karena komunikasi politik PSI Jakarta jelas.

Adapun saran akademis bagi peneliti lain yang ingin melakukan penelitian sejenis, sebaiknya dapat melakukan penelitian PSI Pusat dari aspek komunikasi lain. Saran akademis lainnya bagi peneliti lain yang ingin melakukan penelitian sejenis, sebaiknya dapat melakukan penelitian tentang PSI Jakarta untuk mengungkap lem aibon baik dari sisi komunikasi atau sisi Public Relations.

\section{Ucapan Terima Kasih}

Ucapan terima kasih penulis sampaikan kepada narasumber kunci, narasumber ahli, narasumber DPRD PSI Jakarta, serta masyarakat pemilih PSI Jakarta yang sudah bersedia diwawancara oleh penulis dan memberikan informasi kepada penulis untuk proses pengumpulan data untuk penelitian ini. Penulis juga mengucapkan terima kasih kepada Fakultas Ilmu Komunikasi Universitas Tarumanagara dan pihak yang terkait dalam penelitian ini.

\section{Daftar Pustaka}

Ardial. (2010). Komunikasi Politik. Jakarta : Indeks

Arifin, Anwar. (2011). Komunikasi Politik Filsafat-Paradigma-Teori-Strategi dan Komunikasi. Jakarta: PT. Raja Grafindo Persada

https://nasional.tempo.co/read/1159028/kerap-buat-pernyataan-kontroversial-psiideologi-partai/full\&view $=$ ok

Candraningrum, Diah. Ayu. (2017). Brand Activation, Strategi Komunikasi Pada Lembaga Survei Politik Di Putaran Pertama Pilkada DKI Jakarta 2017. Volume 1, Nomor 1.

Cangara, Hafied. (2013). Perencanaan \& Strategi Komunikasi. Jakarta: Rajawali Pers Cangara. (2016). Komunikasi Politik Konsep, Teori, dan Strategi. Jakarta: PT. Raja Grafindo Persada

Emzir. (2012). Metodologi Penelitian Kualitatif Analisis Data. Jakarta: Rajawali Pers https://www.jawapos.com/jpg-today/19/04/2019/melenggang-ke-dprd-dki-psi-rebutsuara-dari-partai-lama/

Moleong, Lexy J. (2009). Metodologi Penelitian Kualitatif. Bandung: PT Remaja Rosdakarya 
Bella Adha Hendriana Moneter, Eko Harry Susanto: Strategi Komunikasi Politik Partai Baru (Studi Kasus Perolehan Suara Partai Solidaritas Indonesia di DPRD DKI Jakarta Pada Pemilu 2019)

Sujarweni, V. Wiratna. (2014). Metode Penelitian: Lengkap, Praktis, dan Mudah.Yogyakarta: Pustaka Baru Press

Yin, Robert K. (2013). Studi Kasus : Desain \& Metode. Jakarta: Raja Grafindo Persada 